tunity for the determination, and the result obtained is here described. The photograph secured showed two strips of spectra of the corona at the east and west limbs, and, as comparison spectra, three other strips of spectra of diffused sky light were secured symmetrically on the same plate ten minutes after the eclipse. The resulting wave-lengths of the coronal line for the east and west limbs were found to be as follows, each wave-length being the mean of five complete series of measures entirely distinct :-

$$
\begin{aligned}
& \text { East } \lambda 6374.43 \text { (Rowland) } \\
& \text { West } \lambda 6_{374.59} \text {," }
\end{aligned}
$$

Diff. 0.16

This difference corresponds to a velocity of 3.7 kilometres, and, making a correction for the inclination of the slit to the solar equator, gives an equatorial velocity of about 3.9 kilometres per second, a value correct to about 25 to 30 per cent. In the eclipse of 1898 Prof. Campbell, using the green radiation, deduced a tangential velocity of 3.1 kilometres a second $( \pm 2 \mathrm{~km}$. nearly), the diffuse nature of the radiation preventing further accuracy. M. Bosler points out that the corona moves in the same direction as the surface of the sun, and appears to rotate more quickly. The higher levels of the chromosphere show a similar tendency only to a less degree. An apparent increase in velocity with the elevation is thus proved.

The Annual of the Bureau des Longrtudes, I9I5. -The very useful annual for the current year published by the Bureau des Longitudes is as compact as ever, and contains a mine of valuable information very handy for reference. Besides the usual numerous tables useful to the astronomer, several new communications are included. Thus M. G. Bigourdan writes on the subject of the constellations, and after a brief historical sketch gives the co-ordinates of the principal stars and star charts down to $50^{\circ} \mathrm{S}$. latitude. Quite a long article, devoted to stellar spectra and their classification, is written by M. A. de Gramont. The author describes Secchi's classification with illustrations of the type spectra, and then refers to more recent classifications, giving a table showing the correspondence with each other. Sir Norman Lockyer's classification is dealt with in a separate section of the article, and is compared with the Harvard College Observatory classification. A very valuable article, covering 162 pages, is that on "Methods of Examination of Mirrors and Objectives," contributed by $M$. Bigourdan. The article is illustrated by a large number of very useful figures, which will considerably help the reader. The preliminary chapter includes numerous historical references, and this is followed by chapters on general methods of examination, their application to all reflecting surfaces, the examination of mirrors mounted in telescopes, and, finally, a very complete account of the examination and testing of objectives.

Chinese Records of Eclipses.-In the Proceedings of the Tôkyô Mathematico-Physical Society (January, r915, vol. viii., No. I) Messrs. Kiyotugu Hirayama and Sinkiti Ogura discuss the interesting records of early Chinese eclipses. Their working list extends from the earliest solar eclipses to those recorded in the $\mathrm{Ch}^{\prime}$ un Ch'iu. In the case of the latter, the calculations are in progress, and are expected to be soon finished. In the present communication the general plan of the calculations consists in determining the central line and the limiting lines for each eclipse. The eclipses of Shu Ching and Shih Ching are dealt with, and diagrams are given showing some of the limits of visibility.

$$
\text { NO. 2373, VOL. 95] }
$$

\section{TEACHING OF ENGINEERING IN EVENING TECHNICAL SCHOOLS.}

THE "Memorandum on the Teaching of Engineering in Evening Technical Schools" (Circular 894 ), recently issued by the Board of Education, is a very welcome manual of suggestions to teachers and organisers of schools which provide evening classes in mechanical and electrical engineering.

This Memorandum fills nearly sixty foolscap pages, and is divided into nine sections. An introductory section points out the limitations of part-time courses - courses intended for students whose ordinary employment occupies the greater part of their timewhen compared with full-time day courses. The second section, after referring to the fact that some of the serious disadvantages which characterise parttime courses conducted in the evening may be avoided by the growing practice of holding such courses during the day (the junior employees being allowed "time off" in order to attend them), proposes to classify "a complete curriculum of evening instruction" into three stages: the junior course (fourteen to sixteen); the senior course (sixteen to eighteen or nineteen), and the advanced course (eighteen or nineteen to twenty, twenty-one, or twenty-two). Senior courses are to be of two kinds: a minor course, complete in itself, for apprentices to engineering trades; and a major course, incomplete unless it also includes an advanced course, for technical men. The third section of the Memorandum gives outlines of typical major (senior and advanced) courses in mechanical and electrical engineering, and of minor (senior only) courses in some engineering trades. After making, in the next section, some valuable suggestions upon laboratory and class instruction for adolescent evening students, the Memorandum proceeds, in the following four sections, to consider in more detail the teaching of the various subjects which constitute these outline courses. The accommodation and equipment required for the various classes of work already discussed are considered in the ninth and final section.

The Memorandum is thus concerned with all kinds of evening classes intended for persons employed in engineering work, from the apprentice who is beginning to learn a trade to the designer or manager who attends a course of evening lectures delivered by a university professor. By concentrating attention upon evening classes as such, and especially upon those classes which are primarily intended for boys and young men between sixteen and twenty-two years of age, the Board's inspectors have succeeded in producing a document which cannot fail "to assist teachers and organisers to mark out for themselves the schemes of instruction best suited to the conditions of their classes." But this very concentration, to which the Memorandum owes much of its usefulness, will disappoint education committees or directors of education who look to find in it some treatment of the wider educational and economic problems of engineering training, such as the following:-The selection, on democratic lines, of the most suitable boys for each different type of training which should be provided for the different positions in engineering industry; the respective parts to be played, in the preparatory (fulltime) training of engineers, by the elementary school and the junior technical school, the lower secondary school and the senior technical school, and the higher secondary school and the university or technical college; the point at which works training should begin; the co-ordination of practical experience in the shops with instruction in classes inside the works and with outside schools and colleges; and, more generally, the effective co-operation betwean engineering firms and 
education authorities in establishing and administering schemes for the advancement of apprentices.

Perhaps the most important feature of the Memorandum is the distinction which it draws between the major and the minor course. Industrial training has suffered hitherto from a lack of proper appreciation of the differences between the training required by the future artisan (or "tradesman ") on the one hand, and the future "technical" man (whether designer, manager, or commercial representative) on the other. The distinction now drawn does not, lowever, go deep enough. The Memorandum does not sufficiently discourage the prevailing notion that the ideal evening student first enters evening classes at fourteen, and continues to attend such classes for seven years. Thus, instead of insisting that the technical student should remain at. a secondary school until he is at least sixteen, and then, perhaps, enter his major (senior) course when he enters works, the Memorandum contemplates that the technical student and the trade student shall both follow the same junior (evening) course from fourteen to sixteen. It would surely be better that the trade student's own minor course should begin at fourteen instead of at sixteen, and attract him, by its special adaptation to the circumstances of his particular trade, from the moment when he leaves his day school. Moreover, since the trade student will as a rule have less opportunity for general reading in later life, his minor course might well include some "citizenship" subjects, such as industrial history considered at first from the point of view of his particular trade.

More than half of the Memorandum is devoted to "outlines of work" for various recommended courses. This portion is full of most useful suggestions. Some, however, are open to objection, or, at least, to criticism. Thus there is a curious confusion between weight and mass on page 20 (" $g \times$ force $=$ mass $\times$ linear acceleration," which would make $g$ a pure number, independent of the system of units employed). It is also doubtful whether the conception of "work" is really so difficult as to justify the suggested postponement of its introduction until the second year of the senior course. Again, the four years' (major) course in mathematics outlined in the Memorandum might with advantage be less "practical" in its first two years, during which some time might well be found for geometry.

\section{ENGLISH MATHEMATICS.}

THE Mathematical Gazette has recently published a translation of an address delivered by Prof. Gino Loria to the International Congress of Historical Studies. This is a well-proportioned and detached estimate of the main contributions of England to the body of mathematical science, from the earliest available records to the present time. An important suggestion is made that it may be possible to find in some of our libraries manuscript works by some of those early writers who, unlike ourselves, did not hasten to publish their discoveries, and were often surprised by death. In this connection the names of Bradwardine, Richard of Wallingford, John Maudith, and Tonstall are mentioned. Another note is that James Gregory made lengthy stays in Italy, and was therefore probably acquainted with the work of Galileo; so the question arises how far Newton may have been influenced by the achievements of the great Italian philosopher. Prof. Loria suggests inquiry about this as an important piece of research.

Prof. Loria emphasises, with justice, the fact that the renascence of English mathematics in the nineteenth century coincided with a better knowledge and appreciation of work being done abroad. The great ness of Newton, like that of Euclid and Archimedes, had a sort of benumbing effect upon his successors, and even contemporaries; although, of course, there are exceptions, like Maclaurin and Brook Taylor and Waring. It is also pointed out that even now there are certain branches of mathematics which Englishmen persistently ignore, or else treat by obsolete and clumsy, methods. The example given is descriptive geometry; and it is noted that Brook Taylor laid down the principles of this subject in a way perfectly analogous to that adopted long afterwards, and independently, by Fiedler. It is not stated by Prof. Loria, but it is a fact that most of our text-books on descriptive geometry are simply contemptible, from a scientific point of view, and not to be compared with Fiedler's treatise, or the classic work of Monge, which does in the main follow the lines of what we call descriptive geometry, in the restricted sense of orthogonal projection.

Even able students who use these books, and attain great practical efficiency, have no conception at all of the subject as a whole, and are baffled by the simplest problems about traces of lines and planes. So far as we know, there is only one good treatise on descriptive geometry in the English language, and that is in the "Penny Cyclopædia," where so many other treasures have been buried and forgotten. This leads to the remark that Prof. Loria has a proper appreciation of the works of De Morgan, and laments that they are so inaccessible; with this sentiment we cordially agree.

An Italian is as likely as anyone to sympathise with English modes of thought; so any conclusion drawn from this address is likely to be flattering rather than the reverse. We must remember, too, that, when we speak of English mathematicians, we are apt to include such men as Maclaurin, Rowan Hamilton, and Sylvester, who were not Englishmen at all. But even in this inclusive sense of the term "English" one cannot but feel that Continental opinion about English mathematics is almost bound to be analogous to that about English literature in general. Newton is English, and, like Shakespeare, ar Dante, or Goethe, incomparable; but we have lesser men, of a more distinctly national type, who may, perhaps, be more justly appreciated at home than abroad. As an example, we mav instance $W$. H. Fox Talbot, now only vaguely remernbered in connection with photography. As a mathematician he is, of course, not to be compared with Abel; nevertheless he did investigate some cases of Abel's theorem in a very instructive and fundamental way, implicitly showing that the theorem is really a deduction from the known facts about symmetric functions of the roots of an equation, and the elementary theory of partial fractions. We are inclined to believe that the simplest proof of Abel's theorem will ultimately follow the lines that Talbot has indicated.

There are many points in the address to which we cannot refer; but one that deserves mention is that Newton is reported to have said that the style of the ancient geometers is the only one appropriate to any mathematical treatise worthy of the name. Judging by the "Principia," it is probable that this story is authentic.

G. B. $\dot{M}$.

\section{PUBLIC HEALTH.}

THE Medical Officer's Supplement to the fortythird Annual Report of the Local Government Board for $193^{-14}$ (Cd. 7612 , price is. IId.), while it deals mainly with matters primarily of medical interesst, of necessity includes within its scope much that is of value to all scientific minds.

The question of infant mortality occupies a pro.

No. 2373 , VoL. 95 ? 